\title{
Comparison of biocompatibility in cellulose triacetate dialysis membranes with homogeneous and asymmetric structures
}

\author{
Konomi Togo ${ }^{1,2,3^{*}}$, Masahito Yamamoto ${ }^{2,3}$, Motoyuki Imai ${ }^{2,4}$, Keiichi Akiyama ${ }^{3}$ and Akihiro C. Yamashita ${ }^{2}$
}

\begin{abstract}
Background: Historically, cellulose-based materials have been used for manufacturing hemodialysis membranes and remain to date as the commonly used materials. Though cellulose triacetate (CTA) membrane originally has a homogeneous structure, recently, CTA membrane with asymmetric structure (ATA ${ }^{\oplus}$ ) was developed. By a new spinning technology, irregularities or roughness in the inner surface of ATA have become less than those of the conventional CTA membrane. In this study, a comparison was made between CTA and ATA ${ }^{\oplus}$ membranes in order to evaluate the effect of physical structure of the membrane on the biocompatibility.

Methods: We compared the biocompatibility of the following two dialyzers with different triacetate membrane: FB-190UH $\beta$ with CTA, and FA-190F with ATA ${ }^{\oplus}$ (both from Nipro, Osaka, Japan). Heparin of $40 \mathrm{units} / \mathrm{mL}$ was put in a syringe, and test blood was collected from healthy volunteers. Then, the dialyzer and blood circuit were filled with the test blood. Subsequently, the blood was circulated by a roller pump at the rate of $200 \mathrm{~mL} / \mathrm{min}$. We measured the platelet counts, platelet factor 4 (PF4), $\beta$-thromboglobulin ( $\beta$-TG), and CD41 and CD42b platelet surface markers at 30, 120, and $240 \mathrm{~min}$.
\end{abstract}

Results: The average platelet counts at 30, 120, $240 \mathrm{~min}$ in CTA and ATA ${ }^{\oplus}$ were similar. The average $\beta$-TG and PF4 increased from $87.0 \pm 49.0 \mathrm{ng} / \mathrm{mL}$ and $30.7 \pm 17.3 \mathrm{ng} / \mathrm{mL}$ to $1198.5 \pm 1017.2 \mathrm{ng} / \mathrm{mL}$ and $698.2 \pm 574.6 \mathrm{ng} / \mathrm{mL}$ with CTA and to $774.3 \pm 811.6 \mathrm{ng} / \mathrm{mL}$ and $509.0 \pm 417.3 \mathrm{ng} / \mathrm{mL}$ with ATA ${ }^{\oplus}$, respectively. The average expression of CD41 and CD42b decreased to $82.8 \pm 9.7 \%$ and $80.1 \pm 11.6 \%$ with CTA and $81.9 \pm 14.3 \%$ and $80.2 \pm 13.6 \%$ with ATA ${ }^{\oplus}$, respectively.

Conclusions: Observed dialyzers showed less platelet activation as commercial products, and differences between $C T A$ and $\mathrm{ATA}^{\oplus}$ were not significant in terms of PF4, $\beta-\mathrm{TG}, \mathrm{CD} 41$, and CD42b.

Keywords: Hemodialysis, Biocompatibility, Cellulose triacetate, CTA, Dialyzer

\section{Background}

Substantial activation of platelets can occur in the course of hemodialysis [1]. The degree of activation of platelets depends on the materials composing the hollow fibers of the dialyzer [2]. Therefore, improvements of dialysis membranes have concerned biocompatibility. Historically, cellulose-based materials were used for the manufacturing

\footnotetext{
*Correspondence: k.togo@thu.ac.jp

${ }^{1}$ Department of Medical Course, Faculty of Health and Medical Science, Teikyo Heisei University, 2-51-4 Higashiikebukuro, Toshima-ku, Tokyo 170-8445, Japan

${ }^{2}$ Department of Chemical Science and Technology, Faculty of Bioscience and Applied Chemistry, Hosei University, 3-7-2 Kajino-cho, Koganei-shi, Tokyo 184-8584, Japan

Full list of author information is available at the end of the article
}

of hollow fiber membranes and still remain to date one of the most commonly used membranes [3]. Although regenerated cellulose was the mainstream membrane material in the past, the cellulose triacetate (CTA) dialysis membrane is used currently. Though conventional CTA membrane has a homogeneous structure, recently, CTA membrane with asymmetric structure $\left(\mathrm{ATA}^{\circ}\right)$ was developed. By a new spinning technology, irregularities or roughness in the inner surface of $\mathrm{ATA}^{\circ}$ membrane became less than those of the CTA membrane [4]. It is considered that the surface roughness of the membrane surface affects the platelets [5]. However, biocompatibility in ATA ${ }^{\circ}$ membrane has not yet been clearly demonstrated because the $\mathrm{ATA}^{\circ}$ membrane was commercialized recently. In this

(C) The Author(s). 2018 Open Access This article is distributed under the terms of the Creative Commons Attribution 4.0 International License (http://creativecommons.org/licenses/by/4.0/), which permits unrestricted use, distribution, and reproduction in any medium, provided you give appropriate credit to the original author(s) and the source, provide a link to the Creative Commons license, and indicate if changes were made. The Creative Commons Public Domain Dedication waiver (http://creativecommons.org/publicdomain/zero/1.0/) applies to the data made available in this article, unless otherwise stated. 
Table 1 Technical data for test dialyzers

\begin{tabular}{lll}
\hline & FA-190F eco & FB-190UHßeco \\
\hline Manufacturer & Nipro Co., Osaka, Japan & Nipro Co., Osaka, Japan \\
Material of hollow fiber & Cellulose triacetate (asymmetric structure) & Cellulose triacetate (homogeneous structure) \\
Surface area & $1.9 \mathrm{~m}^{2}$ & $1.9 \mathrm{~m}^{2}$ \\
Inner diameter of hollow fiber & $200 \mu \mathrm{m}$ & $200 \mu \mathrm{m}$ \\
Thickness of membrane & $25 \mu \mathrm{m}$ & $15 \mu \mathrm{m}$ \\
Priming volume & $115 \mathrm{~mL}$ & $115 \mathrm{~mL}$ \\
\hline
\end{tabular}

study, a comparison was made between CTA and ATA ${ }^{\circ}$ membranes in order to evaluate the effect of physical structure of the membrane on the biocompatibility.

\section{Methods}

\section{Test dialyzers}

Two kinds of dialyzers were used for this study. We compared the biocompatibility of the following two dialyzers with different triacetate membrane: FB-190UH $\beta$ with conventional CTA, and FA-190F with ATA $^{\circ}$ (both from Nipro, Osaka, Japan). The details of dialyzers were specified in Table 1. The hemodialysis blood circuit produced by Kawasumi Laboratories Co., Ltd. (Tokyo, Japan) was used in this experiment.

\section{Experimental protocol}

First, blood circuits and dialyzers with either CTA or ATA ${ }^{\circ}$ membrane were connected and were rinsed with $1000 \mathrm{~mL}$ of saline solution, respectively. Subsequently, the dialysate side of the dialyzer was rinsed with $2500 \mathrm{~mL}$ of saline solution. Next, heparin of 40 units $/ \mathrm{mL}$ was put in a syringe, and test blood was collected from healthy volunteers. The data of volunteers' blood were specified in Table 2. Each circuit was filled approximately $100 \mathrm{~mL}$ of test blood obtained from one volunteer. Then, the blood drainage side and the blood return side of the circuit were connected using a female-female connector, and the circuits were made into closed. Consequently, the blood was circulated by a roller pump at the rate of $200 \mathrm{~mL} / \mathrm{min}$. The circuit was immersed in a thermostatic bath and maintained at $37^{\circ} \mathrm{C}$. We measured the platelet counts, CD41 and CD42b platelet surface markers, $\beta$-thromboglobulin $(\beta-T G)$, and platelet factor 4 (PF4) at 30, 120, and $240 \mathrm{~min}$ after the initiation of blood circulation. After experiment, the

Table 2 Data of volunteers

\begin{tabular}{ll}
\hline & Data of volunteers (mean $\pm \mathrm{SD}, n=6)$ \\
\hline Males/females & $5 / 1$ \\
Age (years) & $29.7 \pm 11.0$ \\
Hemoglobin ( $\mathrm{g} / \mathrm{dL})$ & $15.6 \pm 0.9$ \\
Hematocrit (\%) & $46.4 \pm 2.0$ \\
White blood cells (counts/ $\mathrm{LL})$ & $5500 \pm 940$ \\
\hline
\end{tabular}

SD standard deviation dialyzers were then filled with $2.0 \%$ glutaraldehyde for immobilization of blood components adhering to the membrane surface. The inner surface of the fiber was exposed using a razor and observed by a field-emission scanning electron microscope (FE-SEM, SU-820 system, Hitachi, Tokyo, Japan) after each experiment.

\section{Statistical analysis}

All data are shown as mean \pm standard deviation. The platelet counts were analyzed by repeated analysis of variance (ANOVA). The CD41, CD42b, $\beta$-TG, and PF4 were analyzed by paired $t$ test. The comparison was considered significant when $p<0.05$. All data were analyzed using Statcel2 (the AddIn forms on Excel).

\section{Results}

The average platelet counts at 30,120 , and $240 \mathrm{~min}$ in CTA and $\mathrm{ATA}^{\circ}$ were similar (Fig. 1). The average expression rates of $\mathrm{CD} 41$ and $\mathrm{CD} 42 \mathrm{~b}$ after the circulation were $82.8 \pm 9.7 \%$ and $80.1 \pm 11.6 \%$ with CTA and $81.9 \pm 14.3 \%$ and $80.2 \pm 13.6 \%$ with $\mathrm{ATA}^{\circ}$, respectively (Figs. 2 and 3 ). Levels of $\beta$-TG and PF4 after the circulation increased from $87.0 \pm 49.0 \mathrm{ng} / \mathrm{dL}$ and $30.6 \pm 17.3 \mathrm{ng} / \mathrm{dL}$ to $1198.5 \pm$ $1017.2 \mathrm{ng} / \mathrm{dL}$ and $698.2 \pm 574.6 \mathrm{ng} / \mathrm{dL}$ with CTA and to $774.3 \pm 811.6 \mathrm{ng} / \mathrm{dL}$ and $509.0 \pm 417.3 \mathrm{ng} / \mathrm{dL}$ with $\mathrm{ATA}^{\circ}$, respectively (Figs. 4 and 5). No adherence of platelets on both membranes was found in observation by FE-SEM

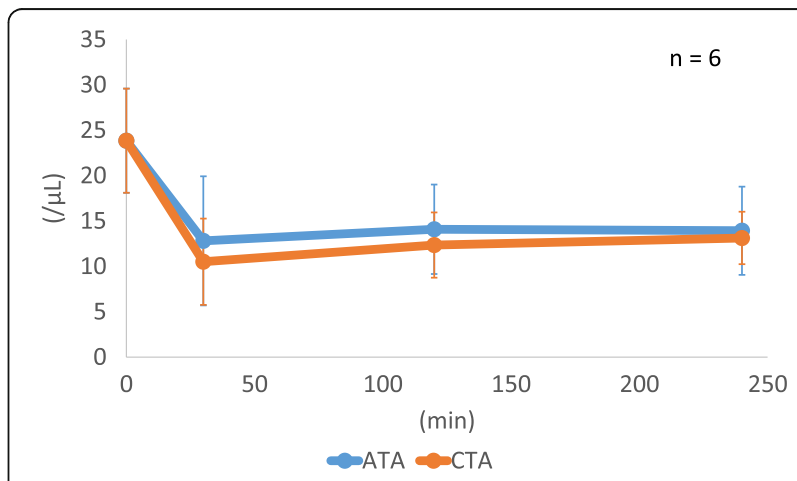

Fig. 1 The variability in the platelet count. At 30 min after initiation of circulation, the platelet counts tended to be lower in CTA than that in ATA ${ }^{\oplus}$. However, there was no significant difference between CTA and $\mathrm{ATA}^{\oplus}(P=0.59)$. CTA cellulose triacetate dialysis membrane, ATA ${ }^{\oplus}$ cellulose triacetate dialysis membrane with asymmetric structure 


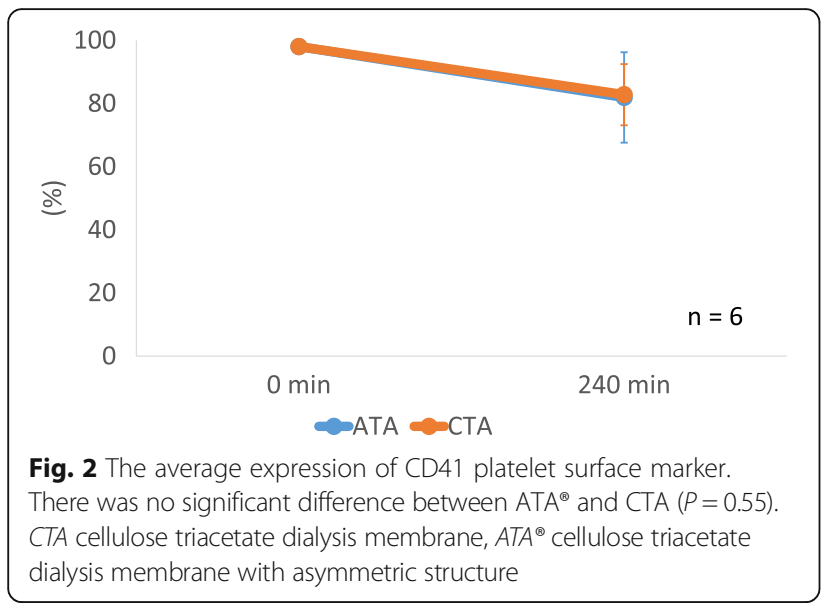

(Fig. 6). The average hematocrit after the blood was filled in the circuit was $35.8 \pm 8.2 \%$ with CTA and $36.5 \pm 5.2 \%$ with ATA $^{\oplus}$.

\section{Discussion}

This study determined the blood compatibility in CTA and $\mathrm{ATA}^{\oplus}$ membrane. We demonstrated that the platelet counts and platelet surface markers (CD41, CD42b) decreased with time, while $\beta$-TG and PF4 increased with time; however, there found no difference between traditional CTA and $\mathrm{ATA}^{\oplus}$ membranes in terms of these markers.

The irregularities or roughness in the inner surface of the $\mathrm{ATA}^{\oplus}$ has become less than those of CTA membrane. Because it is considered that the surface roughness of the membrane affects the platelet [5], we hypothesized that the $\mathrm{ATA}^{\oplus}$ membrane would show less platelet adhesion and activation.

A lot of risk factors for mortality have been proposed in hemodialysis patients [6]. Biocompatibility of hemodialysis membranes affects the survival, morbidity, and quality of life of uremic patients undergoing maintenance HD therapy [7]. It is well-known that interactions between blood

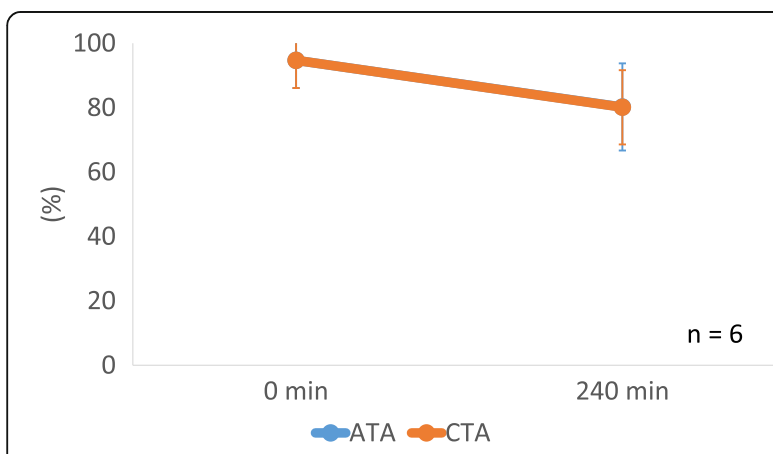

Fig. 3 The average expression of CD42b platelet surface marker. There was no significant difference between ATA ${ }^{\oplus}$ and $C T A(P=$ 0.49). CTA cellulose triacetate dialysis membrane, $A T A^{\circledast}$ cellulose triacetate dialysis membrane with asymmetric structure

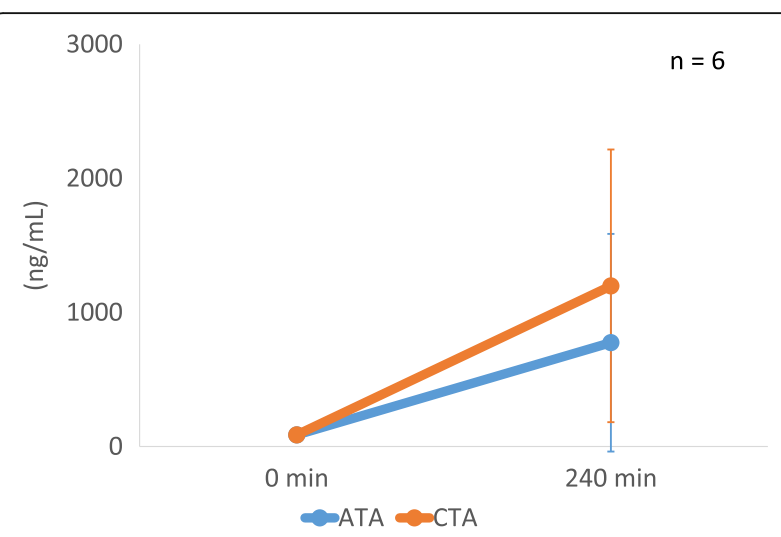

Fig. 4 The variability in platelet activation marker ( $\beta$-TG). Although there was no significant difference, the $\beta$-TG tended to be higher in CTA than that in ATA $^{\oplus}(P=0.87)$. $\beta$-TG beta-thromboglobulin, CTA cellulose triacetate dialysis membrane, $A T A^{\oplus}$ cellulose triacetate dialysis membrane with asymmetric structure

and the hemodialysis membrane include complement activation, direct activation of cellular components, and initiation of the coagulation cascade [8]. Moreover, factors that promote platelet activation and adhesion in dialysis membrane include material, hydrophobicity, charge, number of hydroxyl $(\mathrm{OH})$ groups, method of sterilization, inner diameter of hollow fiber, and roughness of membrane surface [2, 5, 8-12]. Among these factors, it is considered that the hydrophobicity and the roughness of the membrane surface are particularly involved in the activity of platelets. Itoh et al. reported that platelets preferentially adhered to hydrophobic surfaces rather than to hydrophilic surfaces [2]. Moreover, they also reported that hydrophobic membranes possessed higher levels of activity for platelet adhesion and activation than hydrophilic membranes. Actually, there are several reports

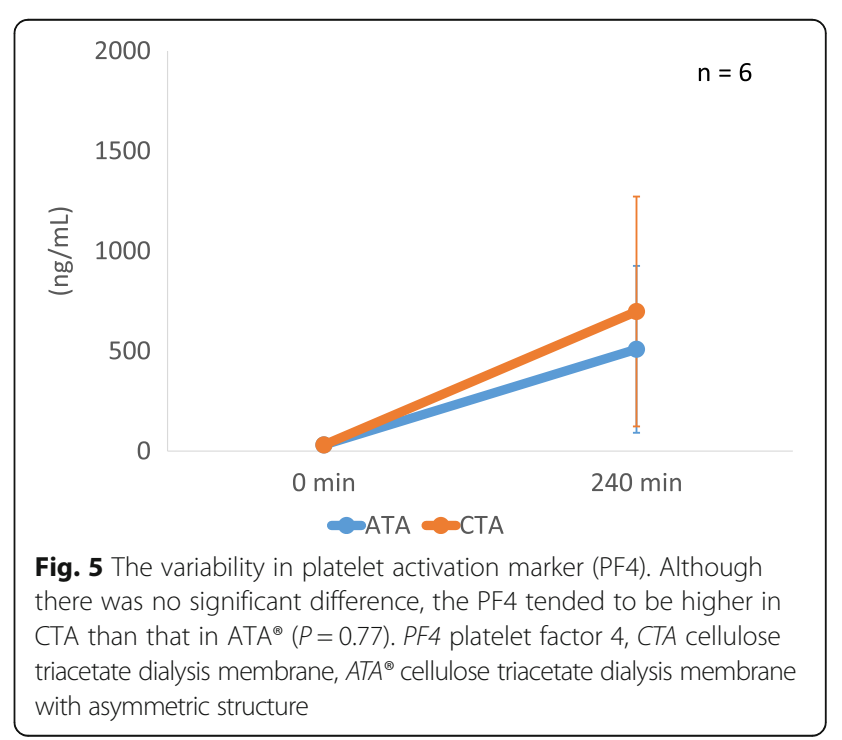




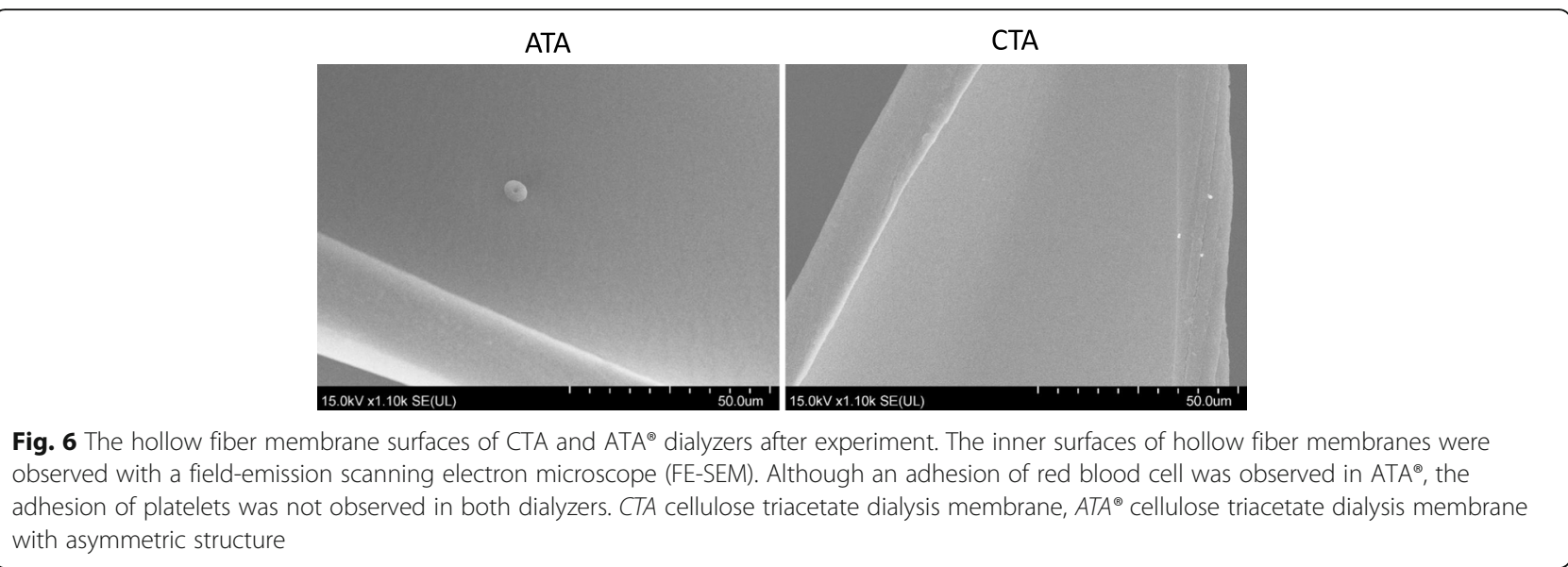

about improvement in platelet counts and activation when the hydrophobic membrane was changed to cellulose membrane [13-16]. In addition, the surface roughness of the $\mathrm{ATA}^{\oplus}, \mathrm{CTA}$, and polysulfone membranes are $4.5,5.5$, and $9.2 \mathrm{~nm}$, respectively [17]. The surface roughness in CTA and $\mathrm{ATA}^{\circ}$ is approximately half of polysulfone membrane. Both CTA and $\mathrm{ATA}^{\circ}$ are hydrophilic in nature; moreover, the membrane surface of CTA and ATA $^{\circ}$ were both smooth. Consequently, we found only a limited amount of adhesion and activity of platelets in both membranes.

Although there was no significant difference in the levels of $\beta$-TG and PF4 in CTA and ATA $^{\circ}$ membrane, these numbers in $\mathrm{ATA}^{\circ}$ tended to be smaller than those in CTA. These results suggested that the activation of the platelets may have been stronger in CTA than in ATA ${ }^{\circ}$.

Above findings included several limitations. This study was performed using healthy volunteers' blood. The reason was that dialysis patients need ultrafiltration or water elimination. If more water is eliminated, the blood within the hollow fiber will become more concentrated, and there is the possibility that the platelets will more easily adhere to the hollow fiber. In order not to be affected by it, samples of blood from volunteers were circulated through ATA $^{\circ}$ and CTA with no ultrafiltration and compared. Moreover, there are several differences between healthy volunteers and dialysis patients. The number of platelets in the patients on dialysis is small [18]. In addition, the platelet count decreases as the hemodialysis period becomes longer [18]. Moreover, the reactivity of the platelet usually increases in the patients on dialysis [19]. Therefore, it may be better to use dialyzers with smoother surface membrane $\left(\mathrm{ATA}^{\circ}\right)$ in the patient on dialysis.

\section{Conclusion}

CTA and $\mathrm{ATA}^{\circ}$ dialyzers have shown less platelet activation, and no statistically significant differences were found in terms of CD41, CD42b, $\beta$-TG, and PF4. Also, the membrane surfaces after the experiment were similar in terms of platelet adhesion according to the FE-SEM observation. Platelet activation may strongly occur depending on the membrane materials and surface roughness of the membrane. It may be better to use dialyzers with smoother surface membrane $\left(\mathrm{ATA}^{\circ}\right)$ because the reactivity of the platelet increases in the patients on dialysis.

\section{Abbreviations \\ ATA : Cellulose triacetate membrane with asymmetric structure; CTA: Cellulose triacetate; FE-SEM: Field-emission scanning electron microscope; PF4: Platelet factor 4; $\beta$-TG: $\beta$-thromboglobulin}

\section{Acknowledgements}

The authors thank all the participants and contributors to the study. In particular, we would like to thank Dr. Kunio Ebine, Kodokan Bldg. Clinic, Tokyo, Japan.

\section{Authors' contributions}

KT planned the study, searched the literature, assessed the studies, extracted the data, analyzed the data, and prepared the article. MY and MI assisted in the data collection. KA and AY helped to draft the manuscript. KT is responsible for the manuscript. All authors read and approved the final version of the manuscript.

\section{Ethics approval and consent to participate}

This study was conducted in accordance with the guidelines of the Declaration of Helsinki and approved by the ethics committees of Kodokan Bldg. Clinic (approval number 2017-2). We obtained written informed consent from all participants.

\section{Consent for publication}

We have also obtained the consent to publish from the participant.

\section{Competing interests}

The authors declare that they have no competing interests.

\section{Publisher's Note}

Springer Nature remains neutral with regard to jurisdictional claims in published maps and institutional affiliations.

\section{Author details}

${ }^{1}$ Department of Medical Course, Faculty of Health and Medical Science, Teikyo Heisei University, 2-51-4 Higashiikebukuro, Toshima-ku, Tokyo 170-8445, Japan. ${ }^{2}$ Department of Chemical Science and Technology, Faculty of Bioscience and Applied Chemistry, Hosei University, 3-7-2 Kajino-cho, Koganei-shi, Tokyo 184-8584, Japan. ${ }^{3}$ Kodokan Bldg. Clinic, 1-16-30 Kasuga, Bunkyo-ku, Tokyo 112-0003, Japan. ${ }^{4}$ Department of Electrical Engineering, Faculty of Engineering, Tokyo University of Science, 6-3-1 Shinjuku, Katsushika-ku, Tokyo 125-8585, Japan. 
Received: 30 April 2018 Accepted: 11 July 2018

Published online: 08 August 2018

\section{References}

1. Daugirdas JT, Bernardo AA. Hemodialysis effect on platelet count and function and hemodialysis-associated thrombocytopenia. Kidney Int. 2012:82:147-57.

2. Itoh S, Susuki C, Tsuji T. The Platelet activation through interaction with hemodialysis membranes induces neutrophils to produce reactive oxygen species. J Biomed Mater Res A 2006;77:294-303.

3. Hakim RM. Clinical implications of hemodialysis membrane biocompatibility. Kidney Int. 1993;44:484-94.

4. Sunohara T, Masuda T. Fundamental characteristics of the newly developed ATA ${ }^{T M}$ membrane dialyzer. Contrib Nephrol. 2017;189:215-21.

5. Koda Y. HDF and biocompatibility. In: Japan HDF Study, editor. HDF Handbook. Tokyo: Nankodo Co., Ltd.; 2000. P. 99-107 (in Japanese).

6. Nagai K, Ueda S, Tsuchida K, Doi T, Minakuchi J. Low serum sodium concentration is a prognostic factor related to current blood glucose level in stable hemodialysis patients: an observational study. Renal Replac Therapy. 2017;3:55.

7. Kodama H, Tsuji A, Fujinoki A, Ooshima K, Ishizeki K, Inoue T. Biocompatibility and small protein permeability of hydrophilic-coated membrane dialyzer (NV) in hemodialysis patients: a pilot study. Renal Replac Therapy. 2017;3:40

8. Post JB. Thrombocytopenia associated with use of a biocompatible hemodialysis membrane: a case report. Am J Kidney Dis. 2010;55:25-8.

9. Kawanishi H. Reaction by contact with dialysis membrane. In: Kawanishi H, Minakuchi J, Masakane I, editors. Biocompatibility of dialytic membrane. Tokyo: Tokyo-lgakusha; 2010. p. 1-8. (in Japanese).

10. Namekawa K, Matsuda M, Yamamoto K, Fukuda M, Sakai K. Surface properties of dialysis membrane and protein adsorption. In: Kawanishi $\mathrm{H}_{\text {, }}$ Minakuchi J, Masakane I, editors. Biocompatibility of dialytic membrane. Tokyo: Tokyo-lgakusha; 2010. p. 16-26. (in Japanese).

11. Kiaii M, Djurdjev O, Farah M, Levin A, Jung B, MacRae J. Use of electronbeam sterilized hemodialysis membranes and risk of thrombocytopenia. JAMA. 2011;306:1679-87.

12. Naito H, Miyazaki T, Kubotsu A, Nihongi Y, Takashima S, Takakura K, Kawahashi M, Oya T. Influence of hollow fiber radius in non-anticoagulant hemodialysis. Jpn J Artif Organs. 1985;14:42-4.

13. Nasr R, Saifan C, Barakat I, Al Azzi Y, Naboush A, Saad M, El Sayegh S. Relationship between platelet count and hemodialysis membranes. Intern J Nephro Renovas Dis. 2013;6:143-7.

14. Olafiranye F, Kyaw W, Olafiranye O. Resolution of dialyzer membraneassociated thrombocytopenia with use of cellulose triacetate membrane: a case report. Case Rep Med. 2011; https://doi.org/10.1155/2011/134295.

15. Kuragano T, Kuno T, Takahashi Y, Yamamoto C, Nagura Y, Takahashi S, Kanmatsuse K. Comparison of the effects of cellulose triacetate and polysulfone membrane on GPIIb/IIla and platelet activation. Blood Purif. 2003;21:176-82.

16. Senou H, Tanigawa Y, Yamauchi T, Miyashita K, Asakura C. Biocompatibility of polysulfone membrane. Kidn Dial. 2003:55:130-4. (in Japanese)

17. Selgas R, Maduell F, Tomo T. New biocompatible haemodiafiltration membrane to enable maximum substitution for sensitive patients. EMJ Nephrol. 2017;5:43-50.

18. Iwamoto $Y$, Ando M, Tsuchiya K, Nihei H. Clinical analysis of thrombocytopenia in chronic dialysis patients. Jpn J Nephrol. 1999;41:712-6. (in Japanese)

19. Kitamoto Y, Makino S, Nagai K, et al. On the platelet aggregation ability of hemodialysis patients. J Jpn Soc Dial Ther. 1985;18:207-12. (in Japanese)

Ready to submit your research? Choose BMC and benefit from:
- fast, convenient online submission
- thorough peer review by experienced researchers in your field
- rapid publication on acceptance
- support for research data, including large and complex data types
- gold Open Access which fosters wider collaboration and increased citations
- maximum visibility for your research: over 100M website views per year
At BMC, research is always in progress.
Learn more biomedcentral.com/submissions

